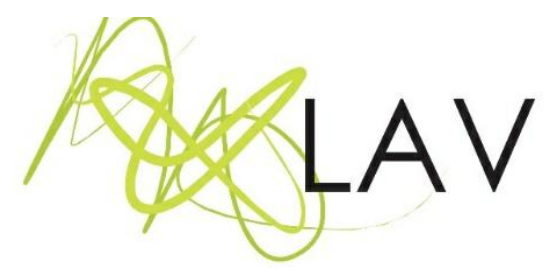

\title{
Uma poética da corporeidade: identidades múltiplas em sala de aula
}

A poetics of corporeity: multiple identities in the schoolroom

Ewelter de Siqueira e Rocha ${ }^{i}$ Universidade Estadual do Ceará

Camila Pinho Limaii Instituto Federal de Educação, Ciência e Tecnologia do Ceará e Secretaria da Educação do Estado do Ceará

\section{Resumo}

Problematizar e implementar um processo de produção de imagens fotográficas que retratam o corpo de estudantes, enquanto estratégia artística e pedagógica para refletir sobre identidade e visão de mundo é o que constitui o cerne deste artigo. Inspirados pelo ensaio Born Nowhere, de Laís Pontes, e recorrendo às reflexões de Stuart Hall, Christine Greiner e Helena Katz, discutimos as relações sutis que perpassam as noções de corpo e identidade no cenário contemporâneo. $O$ estudo tem por substrato etnográfico um projeto desenvolvido com um grupo de estudantes do $1^{\circ}$ ano do ensino médio, em Fortaleza - CE.

Palavras-chave: Corpo, corporeidade, identidades, ensino, fotografia.

\begin{abstract}
Problematizing and implementing a process of photographic image production of the body as an artistic and pedagogical strategy to reflect on identity and worldview are at the heart of this article. Inspired by the work of Laís Pontes called Born Nowhere, and drawing upon the reflections of Stuart Hall and Christine Greiner, we discuss the subtle relation that permeates the notions of body and identity in the contemporary setting. The study has as empirical substrate a project developed with a group of students of the 1st year of High School, in Fortaleza - CE.
\end{abstract}

Keywords: Body, corporeity, identities, education, photography.

Enviado em: 31/07/21 - Aprovado em: 09/11/21

\section{Introdução}

Este estudo tem por substrato empírico um projeto educativo desenvolvido com um grupo de estudantes do $1^{\circ}$ ano do ensino médio, turma do curso Técnico em Produção de 
Moda, da Escola Estadual de Ensino Profissionalizante Leonel de Moura Brizola, localizada na cidade de Fortaleza - CE. ${ }^{1}$

A pesquisa ${ }^{2}$ se vale da sala de aula na condição de laboratório de investigação poética. Recorremos ao processo e ao produto fotográfico como recursos para pensar e produzir imagens que informem e descortinem as relações sutis que perpassam as diversas camadas da percepção relacionadas às identidades dos sujeitos sociais abordados na pesquisa. A partir da implementação do projeto "Poéticas da Corporeidade", refletimos sobre a construção de identidades múltiplas por intermédio de imagens fotográficas do corpo. Durante as ações do projeto, identidade e alteridade se interpenetram, gerando um contraponto sutil, em que indivíduo e sujeito social corporificam distâncias e convergências visuais e afetivas, marcadas por ambiguidades e volições que demarcam um espaço singular de ação no mundo.

Este estudo teve como campo de investigação o ambiente escolar, enfocando a turma do "Técnico Produção de Moda", durante o $1^{\circ}$ semestre do ano 2019. A seguinte turma era predominantemente feminina, acolhendo alunos da faixa etária de catorze a dezesseis anos, com perfis socioeconômicos diversos. A maioria dos estudantes residia em bairros periféricos da cidade de Fortaleza, possuindo orientação sexual diversificada, bastante isenta de preconceitos em relação a gênero e sexualidade. A propósito, no universo da escola, eram sobretudo os alunos do curso Técnico em Produção de Moda que se engajavam nas ações de combate ao preconceito contra os movimentos LGBTI+ e temáticas relativas à identidade de gênero. Outro aspecto que caracteriza esses alunos refere-se à afinidade, que geralmente guardavam com alguma linguagem artística, seja no campo da Música, das Artes Visuais, das Artes Cênicas ou da Dança. A maior parte da turma enfocada neste estudo já possuía familiaridade com a produção de imagens fotográficas, condição que favoreceu o desenvolvimento desta reflexão, para a qual a experiência prévia no campo da fotografia constituiu-se como um elemento crucial.

Orientados inicialmente pelo pensamento de Merleau-Ponty (2014) sobre a compreensão do corpo como sujeito, que articula as relações do "eu" com o "mundo", desenvolvemos e aplicamos um conjunto de atividades em sala de aula que provocaram reflexões coletivas e, posteriormente, culminaram em um exercício de criação artística,

\footnotetext{
${ }^{1}$ O curso Técnico em Produção de Moda faz parte da Escola de Ensino Profissionalizante Leonel de Moura Brizola desde 2015. A proposta desse curso técnico é formar profissionais habilitados a trabalhar nas cadeias produtivas da Moda, como comércio, indústria e serviços.

2 Este texto apresenta um excerto bibliográfico e metodológico da dissertação de mestrado Poéticas da Corporeidade: identidade desveladas em sala de aula, vinculada ao Mestrado em Artes do Instituto Federal do Ceará, na linha Ensino de Arte.
} 
que chamamos "Poética da Corporeidade". Na perspectiva fenomenológica, o mundo não se delimita e tampouco se define a partir de uma racionalidade instrumental, mas sobretudo pela experiência e pela percepção sensível, ou seja, pelo vivido e pelo sentido, em detrimento do efetivamente pensado. Portanto, colocar o corpo e os processos de produção de suas imagens no centro da investigação social é deslocar o olhar em direção às fricções, entre diversos regimes de experiência subjetiva com suas multiplicidades de papéis e corporeidades, produzidos ou emulados para materializar uma autoimagem ou sugerir uma biografia efêmera.

A reflexão sobre identidades plurais, na perspectiva de Stuart Hall (2006), constituiu outra importante diretriz teórica para esse trabalho. $O$ autor investigou uma possível crise de identidade na pós-modernidade, refletindo sobre a tendência de fragmentação e deslocamento da identidade cultural e do pertencimento à cultura. Esse pensamento está alinhado com pesquisas contemporâneas que discutem um possível colapso das identidades modernas, causado por diversas mudanças estruturais da sociedade, fragilizando a "rigidez" de estruturas conceituais como classe, gênero, sexualidade, etnia e nacionalidade. Segundo Hall, tais deslocamentos afetam diretamente as identidades pessoais, "abalando a ideia de nós próprios como sujeitos integrados" (2006, p. 9).

Alinhada ao pensamento de Stuart Hall, a reflexão de Christine Greiner e Helena Katz sobre corporalidade foi bastante importante para inspirar as atividades implementadas em sala de aula. A autora ressalta que "não cabe mais distinguir como instâncias separadas e independentes um corpo biológico e um corpo cultural" (2005, p. 42), perspectiva que nos instigou a buscar na imagem do corpo outros possíveis regimes de identidades, que não fossem depreendidos da aparência ou da performance social externadas no cotidiano ordinário das relações.

A decisão de abordar o tema "fotografia" nas turmas de Produção de Moda surgiu, inicialmente, como uma contribuição prática para a disciplina técnica de Pesquisa Tendência e Produção de Imagem I, na qual os alunos aprendem conceitos técnicos básicos da fotografia aplicados à moda. O que antes fora pensado como uma contribuição prática, passou a ser trabalhado como um campo de investigação poética. Ao longo dos encontros, fomos paulatinamente percebendo a importância de discutir com os alunos, em sala de aula, a constante produção e o intenso compartilhamento de imagens de seus corpos, veiculados em mídias sociais, a maioria denunciando conflitos familiares ou questões relacionadas a gênero e sexualidade. 
É por meio desses aportes teóricos que desenvolvemos as atividades que dão suporte ao nosso estudo, durante as quais, por intermédio dos (des)encontros entre os corpos cultural e biológico dos estudantes, refletimos sobre a constituição de identidades plurais, passíveis de constantes reconfigurações.

\section{Reflexos do não visto}

Neste tópico, apresentamos o processo de execução de uma das etapas do projeto "Poéticas da Corporeidade", desenvolvido junto aos alunos da turma Técnico em Produção em Moda, sujeitos deste estudo. O Projeto dividiu-se em três partes: Fotografia Cega, Personas em Rede e Reflexos. Em cada etapa, a fotografia dos corpos dos estudantes foi concebida enquanto recurso poético e didático para problematizar as relações, e as friç̧ões, entre as noções de identidade e corporeidade. Em função do enfoque estabelecido neste artigo, priorizaremos nesta reflexão o escrutínio da etapa "Reflexos" ${ }^{3}$.

A etapa Reflexos contempla o exercício de leitura de imagens e a criação artística por meio do ato fotográfico. Iniciada com a apreciação do ensaio Born Nowhere, da artista Laís Pontes, a atividade explorou a possibilidade de a fotografia criar e simular diferentes identidades. Nesse momento, fora trabalhado o conceito de identidades plurais (Hall, 2006) discussão que constitui a base conceitual para a execução da prática fotográfica que apresentaremos a seguir, cuja finalidade residiu em instigar os estudantes a retratarem diferentes identidades que compartilham no seu cotidiano.

Detalharemos agora o processo de aplicação, as discussões e os principais resultados referentes à etapa Reflexos, começando com a obra Born Nowhere, de Laís Pontes. A artista criou personagens virtuais em uma plataforma de mídia social a partir de imagens do próprio corpo, as quais foram modificadas digitalmente (Figura 1). Cada personagem ganhou um nome e uma biografia, construídos a partir da colaboração de usuários do Facebook.

\footnotetext{
${ }^{3} \mathrm{Na}$ etapa Fotografia Cega foi ministrada uma aula de introdução aos estudos técnicos em fotografia, visando dar suporte às produções imagéticas feitas ao longo do Projeto. Nessa etapa, foi realizado um exercício de produção de fotografias sem o uso da visão, com o objetivo de provocar um conjunto de experiências sinestésicas conexas ao ato fotográfico. A etapa seguinte, Personas em Rede, explorou a leitura e a produção de imagens voltadas para a construção de identidades nos discursos em rede. Guiados pela leitura das obras das artistas Vivian Maier (1961), Adi korndorfer (2017) e Laura Hospe (2015), os alunos perceberam como a imagem do corpo pode revelar, simular ou omitir questões identitárias. A partir dessa vivência, os estudantes produziram intervenções sobre imagens pessoais (selfies), retiradas de suas redes sociais, recorrendo a desenho, pintura e colagem, com a proposta de explorar a diversidade de percepções que eles têm de si mesmos e as limitações da foto divulgada em condensar essas instâncias de sentido.
} 
A partir da leitura do trabalho Born Nowhere, discutimos com os alunos noções de indivíduo, sujeito social e identidade, ponderando os diferentes papéis que uma pessoa assume ao longo da vida, e como seu corpo se constitui arauto dessa imagem elaborada. Seis imagens (figura 1 ) retiradas do ensaio Born Nowhere foram apresentadas sem uma contextualização prévia sobre a proposta da artista. Os alunos receberam as fotografias como se estas retratassem pessoas diferentes, e para cada uma dessas personas os estudantes elaboraram um perfil social, com dados sobre moradia, profissão, gostos, orientação sexual, entre outros.

Posteriormente, foi apresentada a minibiografia de cada personagem, conforme consta no trabalho da artista, dados obtidos a partir de colaboradores do projeto por meio de uma mídia social. Na construção dos alunos predominou um consenso em relação a questões gerais, como nacionalidade e profissão, mas houve discrepância de opinião na definição de aspectos subjetivos, como orientação sexual, hábitos e gosto pessoal.

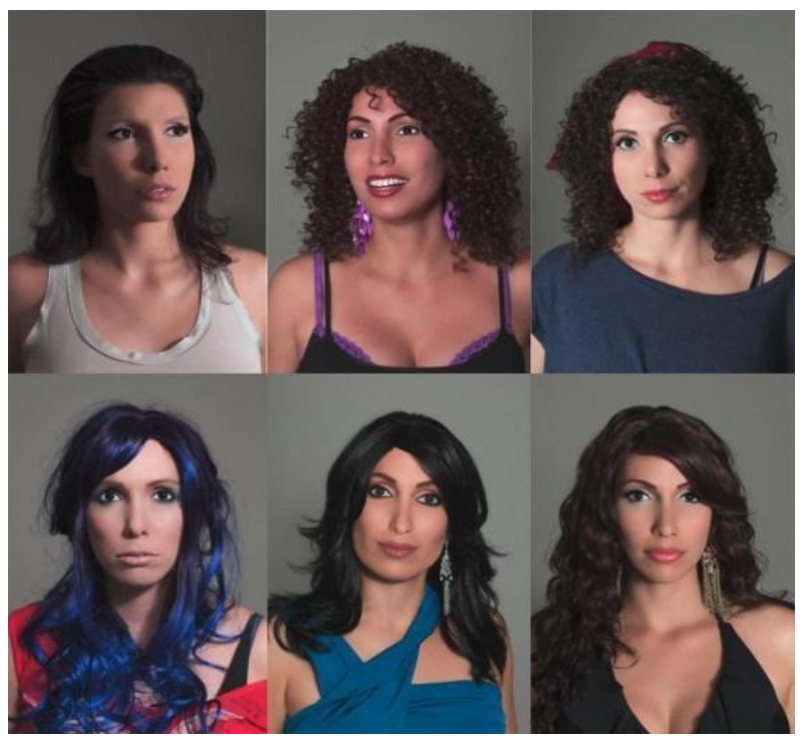

Figura 1: Born Nowhere, Laís Pontes, 2011. Fonte: Pontes, 2011.

A atividade sobre leitura de imagens foi conduzida no sentido de provocar nos alunos um exercício especulativo sobre intersecções e disparidades entre o visto e o nãovisto. Partimos da premissa de que as imagens comunicam e a percepção sobre elas envolvem aspectos externos a obra, não necessariamente retratados plasticamente nas fotografias. Segundo Pillar (2001, p. 3), "o olhar de cada indivíduo está impregnado com experiências anteriores $[. .$.$] , o que se vê não é o dado real, mas aquilo que se consegue$ captar e interpretar acerca do visto, o que nos é significativo". Nesse sentido, a experiência de leitura de imagens visou perceber como as referências socioculturais dos alunos 
agenciam suas percepções sobre o mundo visível, e provocar neles a elaboração de inferências sutis sobre as "invisibilidades" das imagens.

Ao final da leitura, os alunos foram instigados a inferir relações de semelhança entre as pessoas retratadas nas imagens. Alguns se ativeram as semelhanças de ordem física, outros realizaram operações de comparação, baseadas em associações de caráter subjetivo, atribuindo aos personagens hábitos e personalidades específicas. Apenas alguns estudantes mais atentos às sutilezas fisionômicas perceberam que o conjunto de imagens apresentadas retratava a mesma pessoa. Finalizada a discussão, exibimos a proposta do ensaio de Laís Pontes, bem como a forma de interferência realizada nas imagens, destacando as provocações que a artista desenvolveu por intermédio do seu trabalho.

A segunda parte da atividade consistiu em articular o conteúdo do ensaio Born Nowhere com a vida social dos estudantes, levando-os a estabelecer relações entre a obra da artista e sua vida pessoal e social. Mesmo sem aprofundar questões conceituais sobre identidade e alteridade, os alunos, motivados pelo ensaio, ponderavam sobre diferentes papéis sociais que articulavam em seu cotidiano. Foi unânime o reconhecimento sobre diferentes identidades que se assumem em diferentes contextos. Ilustrando essa situação, uma aluna comentou ser filha de pais divorciados e ter hábitos e comportamentos diferentes, dependendo de com qual deles estava. Outro aluno comentou que se sentia de alguma maneira diferente cursando $01^{\circ}$ ano do ensino médio em uma escola profissionalizante, comparado com quando estava na $9^{\circ}$ série, em uma escola regular. Outra estudante confessou haver construído uma autoimagem específica para as redes sociais. Apesar da simplicidade dos depoimentos, eles foram imprescindíveis do ponto de vista pedagógico, uma vez que atestaram a assimilação pelos alunos do conteúdo discutido.

A leitura de imagens proporcionou uma expansão do entendimento da relação do corpo com o seu ambiente. Associando os âmbitos biológico e cultural, Gardner (2001) ressalta que a autoimagem sofre alterações complexas no decorrer da vida. Para o autor, desde o nascimento a criança se insere em um mundo cheio de significados e interpretações, que são possíveis somente por meio de um corpo, destacando que há uma interação contínua entre os corpos, por meio de sensações, sentimentos e ideias. Para Gardner, tanto a dor quanto o prazer transformam a imagem que temos de nós mesmos, afirmando que a imagem de si é uma complexa relação sensorial, perceptiva, motora, neurológica, afetiva e psicossocial, "reconhece-se que a imagem corporal é um constructo multidimensional" (GARDNER, 2001, p. 127). 
Assimilando o pensamento de Gardner sobre a multidimensionalidade da imagem do corpo, trabalhamos com os alunos o conceito de "identidades", tomado com a condição de um construto plural e dinâmico, alinhado ao entendimento de Stuart Hall (2006). O autor defende que o ambiente, as pessoas e as relações fazem com que cada indivíduo construa um modo particular de se perceber dentro desses contextos. Investigando a identidade cultural na Pós-Modernidade, Hall elabora um questionamento sobre a existência de uma crise de identidade, naquilo que ele chama de "modernidade tardia". Como se depreende da citação abaixo, o autor desenvolve a ideia de que há uma tendência de fragmentação e deslocamento da identidade cultural e, consequentemente, da noção de pertencimento a uma cultura específica e localizada.

Um tipo diferente de mudança estrutural está transformando as sociedades modernas no final do século XX. Isso está fragmentando as paisagens culturais de classe, gênero, sexualidade, etnia, raça e nacionalidade, que, no passado, nos tinham fornecido sólidas localizações como indivíduos sociais. Estas transformações estão também mudando nossas identidades pessoais, abalando a ideia que temos de nós próprios como sujeitos integrados. (HALL, 2006, p. 9).

Para o autor, há uma mudança na concepção sobre uma identidade unificada e estável, essa passando a assumir feições fragmentadas, que muitas vezes não se resultam bem definidas ou resolvidas e que podem apresentar contradições entre si. Para Hall, a identidade Pós-Moderna é marcada pela "descontinuidade", condição caracterizada pelo rompimento das esferas ditas tradicionais, decorrente da emancipação dos sujeitos perante as ordens sociais vigentes. Essa conjuntura produz, na contemporaneidade, uma interconexão social sem centro ou eixo condutor, com repercussões tanto na esfera do público quanto em âmbito privado. A projeção que a cultura faz sobre as identidades possui, segundo o autor, uma efígie provisória e variável, uma vez que o indivíduo assume diferentes identidades para diferentes contextos e situações. Para Hall, "a identidade plenamente unificada, completa, segura e coerente é uma fantasia" (2006, p. 14).

Partindo dessa ideia de multiplicidade da identidade, foi solicitado aos alunos que pensassem em três identidades que consideravam mais recorrentes em sua vida. Cada estudante registrou no caderno quem eram essas personas, como cada uma agia, se comportava, se vestia, falava e pensava.

\section{Retratos Múltiplos}

A partir da leitura do ensaio Born Nowhere, introduzimos na sala de aula uma discussão sobre as relações entre corpo e identidade. Exploramos a ideia de corporeidade, 
concebendo o corpo como arauto visual de um eu singular, portador de identidade própria. Na sequência, a cada aluno foi atribuída a tarefa de produzir um ensaio fotográfico, retratando três identidades que julgavam fazer parte de sua vida social. Antes da produção das imagens, realizamos o planejamento técnico e estético relativo à concepção das imagens. Discutimos referências imagéticas que expressavam como cada persona seria fotografada, compreendendo vestimenta, iluminação, cartela de cores, ângulos, poses e composição visual.

Como resultado desse planejamento, os alunos produziram um painel iconográfico que expunha como cada eu seria retratado. A partir de imagens retiradas de websites, os alunos foram organizando um conjunto de fotografias, de modo a criar uma identificação entre elas e as identidades que seriam retratadas no ensaio autoral a ser produzido. $\mathrm{Na}$ figura 2, apresentamos um dos painéis elaborados pelos alunos. Nesse caso em particular, o aluno João 4 relacionou suas identidades a episódios que julgou marcantes em sua história de vida, nomeando-os como "o neto da Dona Raimunda, o artista e o político". O primeiro eu, o neto da Dona Raimunda, faz referência a sua avó, artista circense e sua principal inspiração no mundo das artes. O segundo eu, o artista, está relacionado aos trabalhos e vivências que o aluno tem com as artes cênicas, em especial no universo circense e no teatro de rua, atividade que ainda é muito presente em sua rotina. O terceiro eu, o político, faz referência à valorização de seu corpo negro e à exposição da sua orientação sexual, sendo esta identidade que o aluno recorre no ambiente escolar e em alguns espaços coletivos.
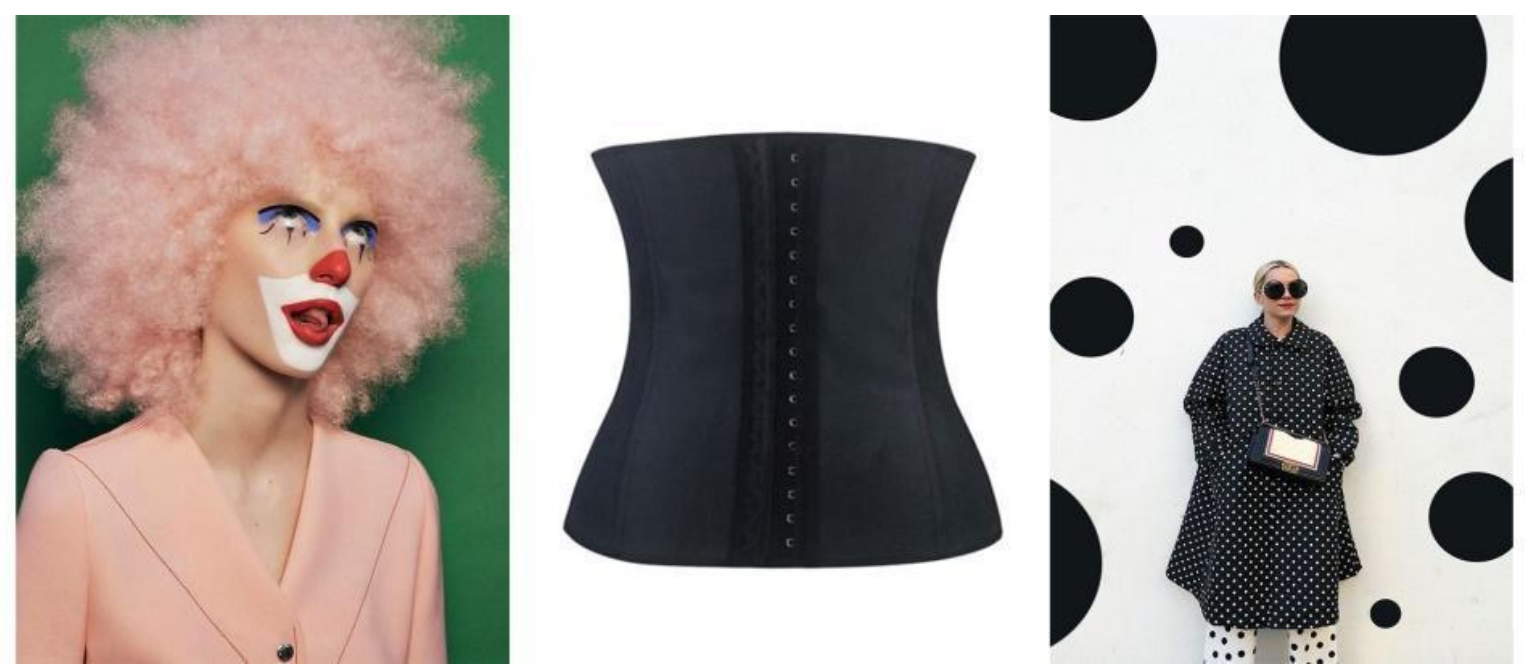

Figura 2: Painel iconográfico do aluno João.

Fonte: Pinterest (2019).

\footnotetext{
${ }^{4}$ Os nomes utilizados para designar os estudantes referidos no texto tratam-se de pseudônimos.
} 
Para a sequência da atividade, os quarenta e cinco alunos na turma foram divididos em nove equipes de cinco integrantes. De posse de uma única câmera fotográfica, os alunos de cada equipe fotografaram-se em uma permuta de duplas, de forma que todos participassem da atividade, tomando como referência para a realização de cada ensaio fotográfico o painel iconográfico que cada estudante previamente havia elaborado 5 .

No dia do ensaio fotográfico, cada integrante vivenciou a condição de fotógrafo, assistente e modelo. Foi destinado um tempo de cinquenta minutos para cada equipe. Durante o ensaio fotográfico, os alunos a serem fotografados expuseram em detalhes como eram cada uma das personas retratadas no painel, fornecendo, inclusive, elementos sobre a sua história de vida e aspectos da sua personalidade. Os dois contextos sociais que predominaram nos ensaios estão associados ao âmbito familiar e ao ambiente escolar. Já o terceiro contexto, vinculou-se a um espaço pessoal de "intimidade", geralmente relacionado a questões políticas, de gênero ou afetividade. Apresentamos, a seguir, três dos ensaios fotográficos produzidos ao longo da atividade, começando pelo desenvolvido a partir do painel iconográfico apresentado previamente (Figura 3).
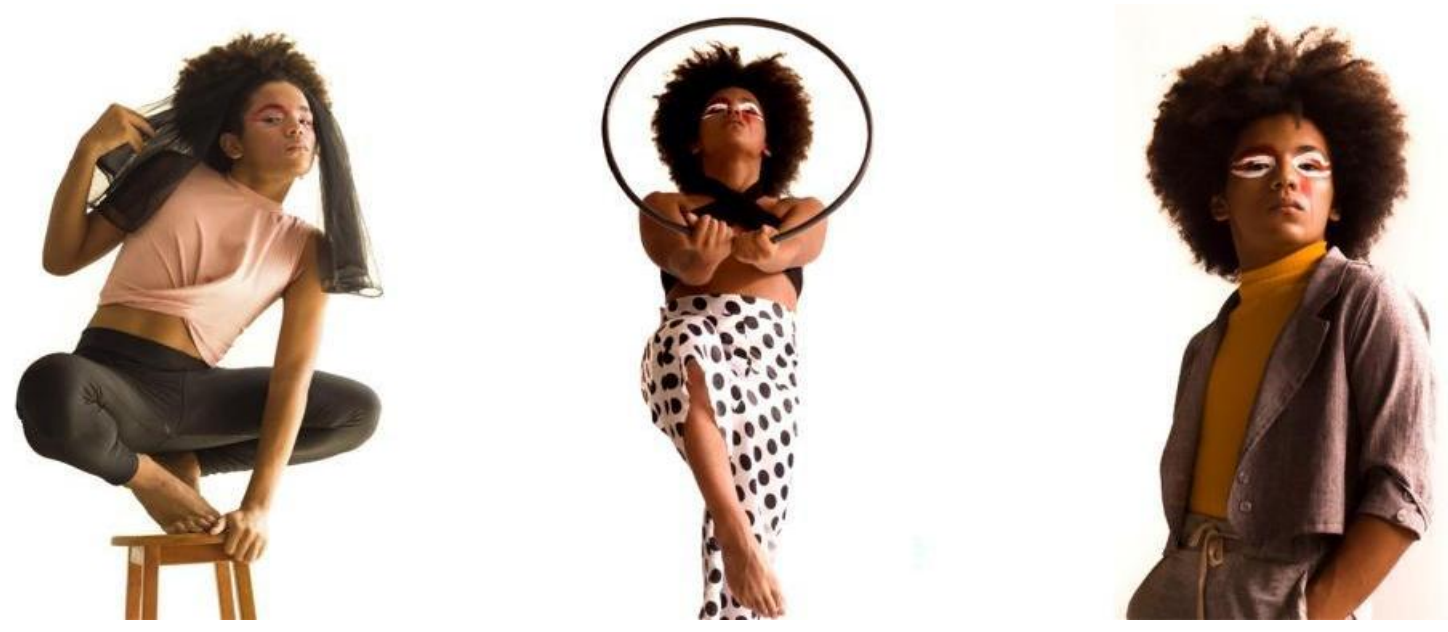

Figura 3: Retratos múltiplos do aluno João.

Fonte: Arquivo pessoal dos autores (2019).

As orientações fornecidas para a elaboração do ensaio apresentado em sequência (Figura 4) da aluna Ana, tiveram como referência estados afetivos compatíveis com situações específicas de vida da aluna fotografada. A instrução para o primeiro retrato baseou-se na forma a partir da qual os alunos da escola a enxergam: uma pessoa

\footnotetext{
${ }^{5}$ As fotos foram produzidas no galpão da base técnica do curso de Produção de Moda, espaço destinado a eventos e aulas práticas do Curso. Nesse espaço, os alunos montaram um camarim de apoio, local que favoreceu a troca de roupas, a produção de maquiagem, a construção de cenários e iluminação. Todas as fotos foram realizadas em um fundo branco neutro, para que as produções tivessem uma padronização estética.
} 
sorridente e espirituosa, solicitando expressamente ao fotógrafo que a foto a retratasse da maneira mais espontânea possível. Nas palavras da aluna, a segunda fotografia representa o seu "eu sonhador". Ela relatou que tinha desejos de cursar faculdade e que desde cedo era apaixonada por literatura. Sua última foto retratou o seu "lado feminino". Segundo ela, a pose de costas fala sobre seu processo de puberdade, "uma menina se transformando em uma mulher".

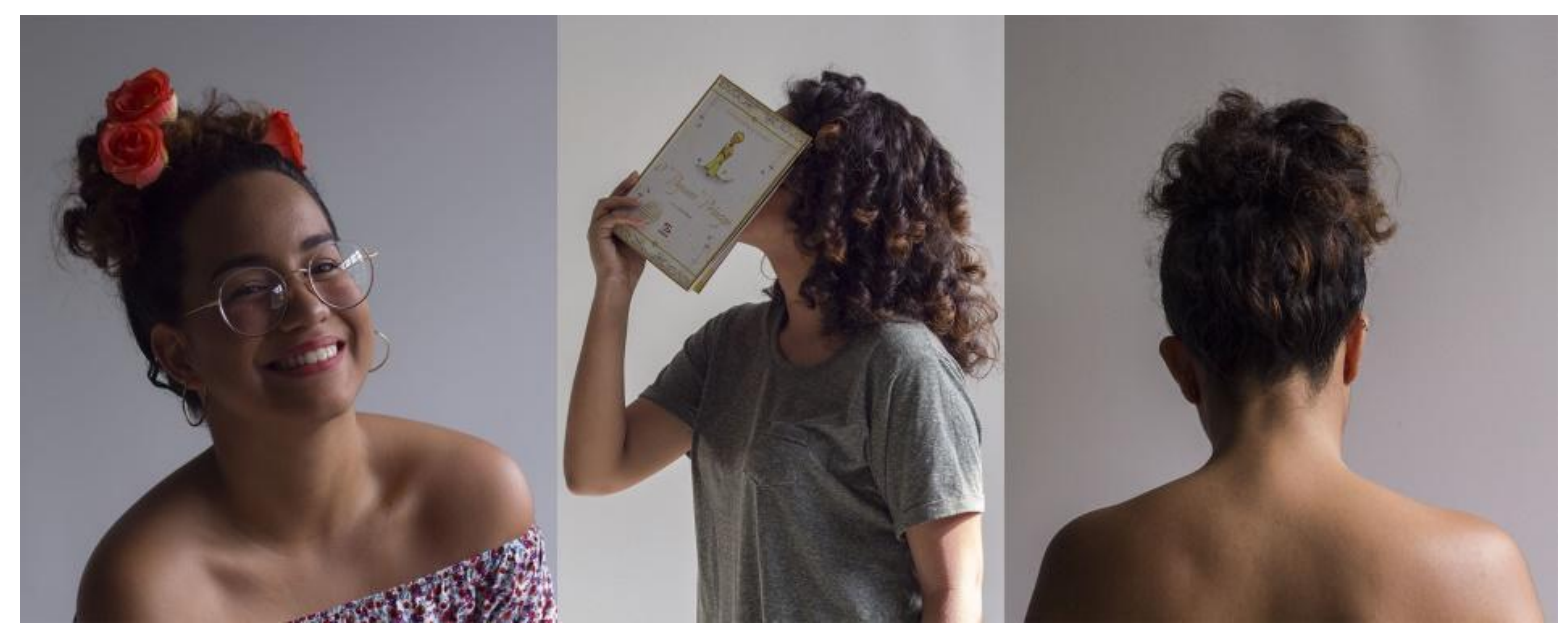

Figura 4: Retratos múltiplos da aluna Ana.

Fonte: Arquivo pessoal dos autores, (2019).

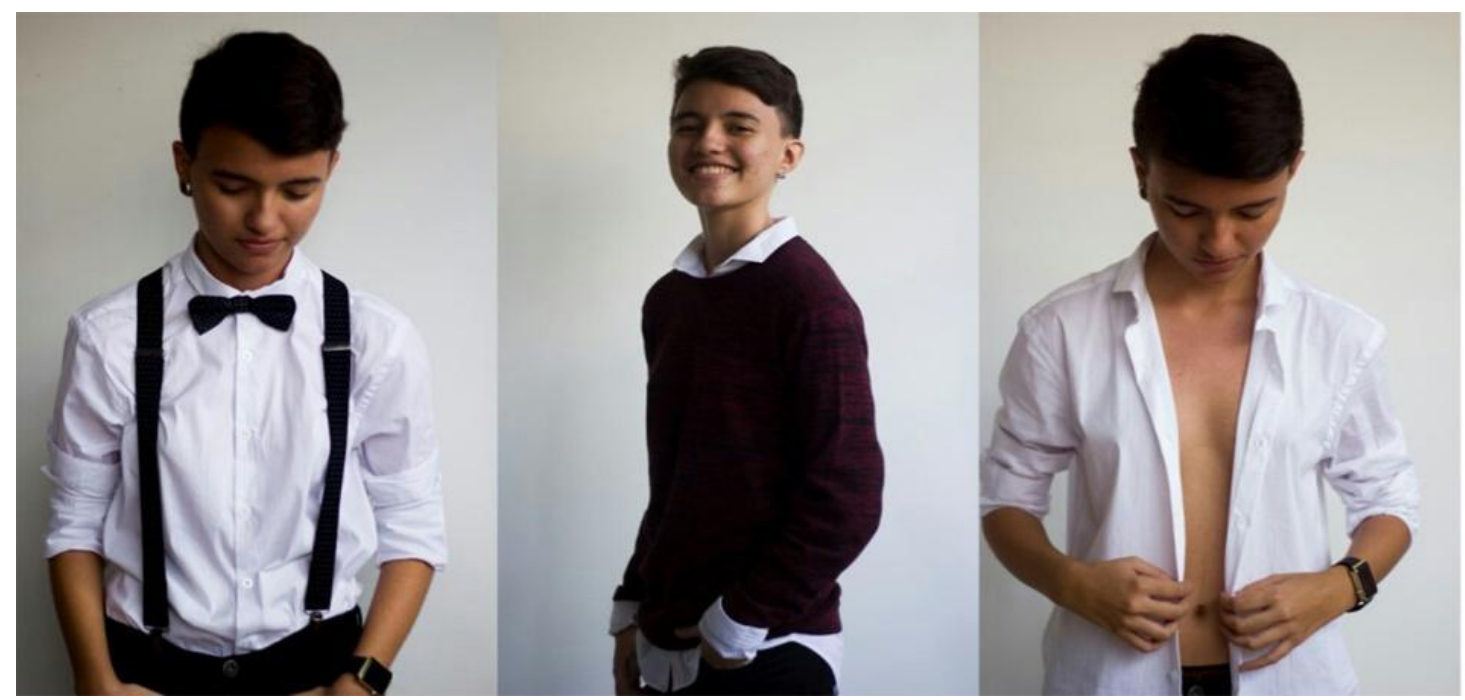

Figura 5: Retratos múltiplos da aluna Maria.

Fonte: Arquivo pessoal dos autores, (2019).

A aluna Maria retratada no ensaio acima (Figura 5) elaborou o seu ensaio a partir de personas masculinas. O seu painel iconográfico já denunciava o teor de seu ensaio futuro, pois tanto as roupas como as fotos inseridas eram de homens. As orientações passadas para quem a fotografou ressaltavam uma busca pessoal em relação a uma corporeidade com a qual a aluna se identificava. Além de questões de gênero, cada imagem 
apresentava um estado emocional bastante singular. A primeira, retratando uma pessoa introspectiva; a segunda apresentando uma feição de contentamento; e a última elaborando uma imagem sutil sobre sua orientação sexual, mesclando elementos visuais dos estereótipos masculinos e femininos.

\section{Últimos vislumbres}

O projeto Poéticas da Corporeidade teve como desafio utilizar a fotografia como um dispositivo capaz de problematizar e emular corporeidades e identidades múltiplas, refletindo sobre possíveis cooperações ou tensões entre a vida social e a dimensão subjetiva dos alunos. Foi um projeto que trabalhou essencialmente com imagens, objetivando encontrar, através da fotografia dos corpos, rastros de identidades multifacetadas. No ensaio fotográfico dos alunos, apresentado no tópico anterior, ficou patente a relação da imagem do corpo com identidades que caminham por diferentes pendores da subjetividade. O corpo, além de ser o sujeito e objeto da pesquisa, constituiuse importante meio de comunicação entre identidade veladas e papéis sociais.

A interação ativa entre corpo e mundo é tematizada por Merleau-Ponty, quando ressalta que essa cooperação se estabelece tanto na esfera do sensível quando no âmbito simbólico, frisando o papel da experiência estética enquanto instância, capaz de expandir a dimensão expressiva do corpo e a percepção sobre a vida. Por meio do Projeto, buscamos aguçar a sensibilidade sobre o estatuto da corporeidade, na busca de provocar nos alunos novas percepções acerca de sua identidade. Como ressalta Merleau-Ponty "A apreensão das significações se faz pelo corpo", destacando ainda que o processo de aprendizagem sobre o mundo pressupõe a aquisição de um certo estilo de visão, portanto, "um novo uso do corpo próprio, é enriquecer e reorganizar o esquema corporal" (2004, p. 212). Para Merleau-Ponty, o corpo é um ser sensível, perpassado por fatores culturais históricos e sociais, preponderantes para a percepção que os sujeitos constroem de si:

Nosso contato conosco sempre se faz por meio de uma cultura, pelo menos por meio de uma linguagem que recebemos de fora e que nos orienta para o conhecimento de nós mesmos (MERLEAU-PONTY, 2004, p. 49).

O projeto "Poéticas da Corporeidade", que desenvolvemos em sala de aula alia-se ao entendimento de que a percepção e a representação do próprio corpo constituem um elemento ativo na construção da personalidade de um indivíduo. O processo de elaboração de cada imagem do ensaio fotográfico produzido pelos alunos, assim como o produto visual 
obtido mostraram-se mais associados a representações simbólicas de identidades latentes do que a estereótipos sociais efetivamente personificados no cotidiano, agregando ao binário estabelecido por Ponty - o Biológico e o Cultural - uma dimensão extremamente sutil relacionada a intimidades e constrangimentos vivenciados pelos alunos, cuja superação ou desvelamento passa necessariamente por um ato de incorporação (embodiment) de uma identidade particular.

Por intermédio do processo de criação e análise das imagens produzidas ao longo da etapa Reflexos, componente do projeto "Poéticas da Corporeidade", refletiu-se sobre como os alunos da turma de Produção de Moda constroem internamente suas representações de mundo e como os aspectos externos modelam e constrangem uma forma visível de corpo. Alinhamos nossa reflexão ao pensamento de Le Breton (2007), quando este autor ressalta que a compreensão corporal é um fenômeno social e cultural, sendo o corpo objeto de representação, objeto imaginário e objeto simbólico. Nessa perspectiva, o corpo é um vetor de significações, que personifica as relações construídas com o mundo:

Moldado pelo contexto social e cultural em que o ator se insere, 0 corpo é o vetor semântico pelo qual a evidência da relação com o mundo é construída: atividades perceptivas, mas também expressão dos sentimentos, cerimoniais dos ritos de interação, conjunto de gestos e mímicas, produção da aparência, jogos sutis da sedução, técnicas do corpo, exercícios físicos, relação com a dor, com o sofrimento, etc. Antes de qualquer coisa, a existência é corporal (Le Breton, 2007, p. 7).

A leitura e discussão do trabalho de Laís Pontes e da prática fotográfica nele inspirado, introduziu para os alunos a discussão sobre multiplicidade e a fragmentação das identidades na Pós-Modernidade. Ao vivenciarem a experiência de produzirem imagens associadas a múltiplas identidades, os alunos dilataram a noção de corporeidade, percebendo outras instâncias e potências de sua imagem. Transpuseram as fronteiras do biológico e de modelos imperativos de corpo, encarnando na fotografia elaborada identidades híbridas, marcadas por regimes sutis de aparências, que transitam entre o que é socialmente arbitrado, intimamente pretendido e culturalmente possível.

No ensaio dos alunos foi latente a relação da imagem do corpo com as construções de suas identidades. Segundo Erthal (1986, p. 44), "a noção do corpo é essencial para a consolidação da identidade. As sensações e os movimentos dão a consciência constante de quem a pessoa é, pois à medida que ela se experimenta no mundo, vai-se conhecendo". No caso da aluna Samira, por exemplo, foi possível ver as sutilezas que permearam, tanto na escolha de suas roupas quanto as poses escolhidas para seus retratos, imagens que, 
antes de se transformarem em algo fotografável, integravam uma imagem do eu velada pelo contexto da aluna. As imagens de seu ensaio possibilitaram experimentar sua visão interior de ser-no-mundo.

As imagens feitas pelos alunos se distanciaram do cotidiano social e se aproximaram do que é intimamente vivenciado por seus autores. O corpo como "parte mais material e visível do eu" (ERTHAL 1986, p. 40) exibiu, nas produções do projeto, gestos, formas e intenções de sujeitos, ao mesmo tempo, singulares e multifacetados. A fotografia, como um jogo de espelhos, proporcionou aos alunos se lançarem para fora de si mesmos, na busca de se descobrirem e se perceberem, mas sempre imersos em um delicado jogo de imaginação e de vontades.

\section{Referências}

ERTHAL, Tereza Cristina S. A auto-imagem: possibilidades e limitações da mudança. Revista Psicologia Clínica, Rio de Janeiro, 1986.

GARDNER, Howard. Inteligência: um conceito reformulado. Tradução Adalgisa Campos da Silva. Rio de Janeiro, Editora Objetiva, 2001.

GREINER, Christine e KATZ, Helena. O Corpo como pista de estudos interdisciplinares, Editora Annablume, São Paulo, 2005.

HALL, Stuart. A identidade cultural na pós-modernidade. 10. ed. Rio de Janeiro: DP\&A, 2006.

LE BRETON, D. A sociologia do corpo (S. M. S. Fuhrmann, Trad., 2. ed. Petrópolis, Rio de Janeiro, Editora Vozes, 2007.

MERLEAU-PONTY, M. Fenomenologia da percepção. Rio de Janeiro: Freitas Bastos, 2004.

PILLAR, Analice Dutra. A educação do olhar no ensino das artes. Porto Alegre: Mediação, 2001.

PONTES, Lais. Born Now here. 2011.

\footnotetext{
' Professor/Coordenador do Curso de Música da Universidade Estadual do Ceará (UECE) e Professor do Programa de Pós-graduação em Artes do Instituto Federal do Ceará - IFCE. Graduado em Matemática pela Universidade Federal do Ceará, graduado em Música pela Universidade Estadual do Ceará, mestre em Etnomusicologia pela Universidade Federal da Bahia e Doutor em Antropologia Social pela Universidade de São Paulo - USP. Possui uma produção acadêmica abrangendo os campos da Fotografia, Música, Educação e Antropologia Visual. Suas pesquisas abordam as seguintes temáticas: educação musical;
} 
fotografia e memória; a estética e as performances do sagrado relativas ao catolicismo popular nordestino; estudo das relações entre música e localidade; o campo da arte na escola e no terceiro setor. Utiliza a fotografia e o filme etnográfico como métodos e fontes de pesquisa, havendo também realizado diversas exposições fotográficas e trabalhos audiovisuais autorais. Foi coordenador do Programa Institucional de Bolsas de Iniciação à Docência - PIBID (2013/2017). Com artista, desenvolve trabalhos na área de composição de trilhas musicais, design sonoro, fotografia e cinema. É pesquisador associado da Universidade de São Paulo, integrando os grupos PAM - Pesquisa em Antropologia Musical (USP/CNPQ) e GRAVI - Grupo de Antropologia Visual (USP/CNPQ). É membro do grupo de pesquisa Cultura Brasileira, Educação e Práticas Pedagógicas (UECE/CNPQ). Líder do grupo Pesquisa em Música, Cultura e Educação Musical (UECE/CNPQ).

ii Artista, pesquisadora e educadora com mestrado em arte e ênfase no ensino pelo Instituto Federal de Educação, Ciência e Tecnologia do Ceará (IFCE), utiliza a sala de aula como campo de pesquisa poético e pedagógico. Possui licenciatura em Artes Visuais também pelo IFCE, especialista em História da Arte pelo Centro Universitário Claretiano. No campo estético, usa a fotografia para desenvolver pesquisas e ações poéticas sobre o corpo, espaço e memória. Atua como professora da disciplina de Arte em Fortaleza pela rede pública de ensino do estado do Ceará.

Como citar esse artigo:

ROCHA, Ewelter de Siqueira; LIMA, Camila Pinho. Uma poética da corporeidade: identidades múltiplas em sala de aula. Revista Digital do LAV, Santa Maria: UFSM, v. 14, n. 3, p. 131-144, set./dez. 2021. 